Transactions, SMiRT-25

Charlotte, NC, USA, August 4-9, 2019

Division V

\title{
DEVELOPING AND NATURAL SCALE TESTING OF THE 3D BCS BASE ISOLATION SYSTEM
}

\author{
Victor Kostarev ${ }^{1}$, Dr. Peter Nawrotzki ${ }^{2}$, Petr Vasilev ${ }^{3}$, Maksim Vaindrakh $^{4}$ \\ ${ }^{1}$ Director, CKTI-Vibroseism, Saint-Petersburg, Russia (victor.kostarev@gmail.com, \\ vkostarev@cvs.spb.su) \\ ${ }^{2}$ CEO, GERB Vibration Control Systems, Berlin/Essen, Germany (peter.nawrotzki@gerb.de) \\ ${ }^{3}$ Principal, CKTI-Vibroseism, Saint-Petersburg, Russia (pvasilyev@cvs.spb.su) \\ ${ }^{4}$ Leading Engineer, CKTI-Vibroseism, Saint-Petersburg, Russia (mvayndrakh@ @ cvs.spb.su)
}

\begin{abstract}
The most common seismic isolation systems as various modifications of LRB, Rubber Pads and PFB bearings are effective for protection against horizontal seismic excitation. At the same time these devices could lead to a significant amplification of an isolated structure's seismic response in the vertical direction due to a coupling phenomenon of their horizontal and vertical components and certain stiffness in the vertical direction. These effects could provide an essential reduction of the total seismic isolation system's (SIS) efficiency and in some cases remain in structure seismic response approximately at the same level or even higher than for a rigidly supported structure.

This paper presents results of optimization and efficiency analysis for the new developed 3D seismic isolation base control system SIS BCS for a typical NPP Reactor Building (RB) with 3D coil spring isolators and separately located 3D dampers.
\end{abstract}

\section{INTRODUCTION}

In general, the SIS efficiency depends on the combination of elastic properties of isolators and system damping. The tests of a 3D Floor Seismic Isolation System performed in Japan at the IHI 35-ton shaking table have confirmed an evident but unexpectedly positive influence of system damping obtained in test and in numbers, Ochi et al. (1990). Upgrading the Floor Air Bearing Isolation System damping from 3\% to $14 \%$ by changing the features of $3 \mathrm{D}$ viscoelastic variable dampers had a double effect, first, in $16 \%$ increase of the efficiency of SIS acceleration isolation and, second, the same time in decrease by 1.5 times of relative super- and substructures displacements. This has given rise to an idea of developing a 3D SIS with capacities that would satisfy rather controversial demands for good isolation efficiency along with limited umbilical displacements using the optimization procedure, Vasilyev (2013).

A conventional SIS design involves the use of existing or permanently appeared new isolation devices, which have fixed stiffness and damping parameters. Subsequent seismic analysis shows clearly defined positive and negative features of the SIS devices implemented. The vertical seismic excitation and other possible dynamic impacts on the structure are usually excluded from consideration and the SIS efficiency is shown in the horizontal direction only. Even the latest edition of ASCE 4-16 has a very controversial position on the issue. One more concern in using the conventional SIS for 3D isolation appeared after relevant experiments have been carried out at the E-Defence shaking table in Japan where a full-scale building was equipped with Lead Rubber Bearing (LRB) and Friction Pendulum Bearing (FPB) bearings and subjected to 3D seismic excitation. While in cases of 1D and 2D horizontal excitations both SI systems demonstrated relatively good behaviour and isolation properties, the addition of vertical seismic impact has brought the building structure practically to a non-isolated state, Furukawa (2012). 
A newly developed SIS or Base Isolation (BI) approach suggests the initial definition of a Demand in a form of some performance criteria and then using an optimization process and corresponding goal function to obtain necessary parameters of the SIS. The target is to get the optimal 3D SIS in terms of sufficient 3D acceleration isolation including efficient vertical seismic isolation and appropriate 3D seismic displacements for a current structure and site specific seismic data.

The optimization process with variable isolators' stiffness and system damping should provide the optimal values of SIS horizontal and vertical stiffness separately (basic natural frequencies of the structure) and reasonable system's damping to limit relative umbilical displacements according to the demand. This study has the goal to develop an optimal or close to optimal 3D isolation system enables to secure SIS advantages and mitigate known limitations in base isolation approach, Sollogoub (2018).

\section{SIS OPTIMIZATION MODEL}

It is obviously that there are no universally optimal characteristics (elastic properties, natural frequencies, ductility and damping) for all structures, buildings and sites. These values depend to a high degree upon the following three primary parameters:

- Inertia, dynamic properties, geometry and other features of an isolated superstructure;

- Peculiarities of the seismic input, site specific spectra, acceleration time-histories $(\mathrm{TH})$, its frequency content and duration;

- The goal established in achieving the isolation parameters and relative super and substructures displacements, e.g. some Goal Function in isolation efficiency and umbilical displacements.

The results given below show the parameter optimization for this SIS of a PWR Reactor Building (RB) having approximately 80 meters in height and 20 meters in elevation of the Gravity Center that corresponds to the most important location of the reactor supports. Due to a large amount of calculations the optimization process required using a simplified stick RB model, which included 18 degrees of freedom (DoF) plus 3 DoF for the "seismic" mass as shown in Figure 1. Isolation Units (100 conditional devices) were modelled with linear springs and viscous elements.

Artificial time-histories correspond to the UHRS 7\% damping spectra of one of NPP sites, are scaled to $0.4 \mathrm{~g}$ in the $\mathrm{X}, \mathrm{Y}$ directions and in $2 / 3$ ratio to the $\mathrm{Z}$ vertical component. The comparison of the target spectrum to the artificial time-histories spectra can also be found in Figure 1.

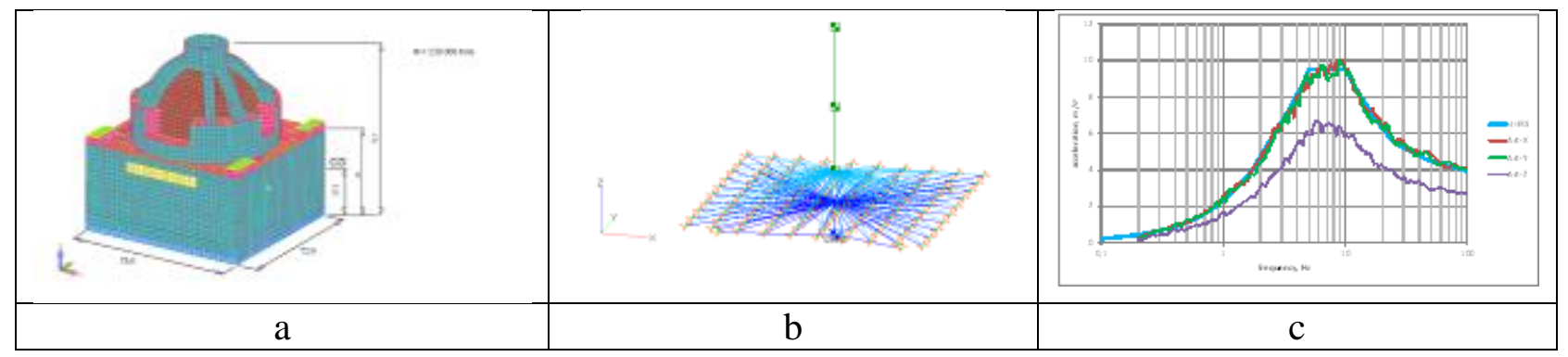

Figure 1. PWR RB 3D view (a), Stick Analysis Model (b), UHRS site specific seismic spectra (c).

A combination of the following two parameters was adopted as the Goal Function: the peak acceleration at the reactor support level (A) and maximal displacement at isolation unit (D). The goal function was written as:

$$
G F=\left(\frac{A}{A w}\right)^{2}+\left(\frac{D}{D w}\right)^{2}
$$


Aw and Dw in formula (1) are the weight coefficients. Aw and Dw represent undesirable values of the response superstructure acceleration and its relative displacement against substructure. In this research, the following weights were adopted: $\mathrm{Aw}=0.4 \mathrm{~g}$ (no isolation efficiency) and $\mathrm{Dw}=100 \mathrm{~mm}$ as a limit for the self-compensation ability of connecting (umbilical) distribution systems.

Nominal frequencies as well as nominal damping for horizontal and vertical directions (4 parameters altogether) are used as optimization parameters. The nominal frequency is defined by the following formula:

$$
f_{N}=\frac{1}{2 \cdot \pi} \sqrt{\frac{C}{M}}
$$

The nominal damping is defined by the following formula:

$$
d_{N}=\frac{B}{2 \cdot \sqrt{C \cdot M}}
$$

Where: $\mathrm{M}$ is the mass of the building; $\mathrm{C}$ is the total stiffness of isolation units; $\mathrm{B}$ is the total viscous resistance of isolation units.

It is obvious that the real frequencies and damping of the system differ from the nominal parameters indicated, so they are conditional for the purposes of analysis and simplification of the optimization process.

Preliminary calculations performed included the optimization using the Hooke-Jeeves method and were carried out without any limitations set upon the parameter values. It turned out that damping growth occurred in both directions up to the critical damping value. It was subsequently decided to limit damping to $20 \%$ of the critical value in order to exclude overdamping and stiffening of the system. As a result, only two parameters remained arbitrary, i.e. the nominal frequencies in the horizontal and vertical directions. In such case, it became possible to construct the goal function surface shown in Figure 2 . The nominal frequencies in the horizontal and vertical directions have the variation within the range from 0.15 $\mathrm{Hz}$ to $3 \mathrm{~Hz}$ with $0.15 \mathrm{~Hz}$ increments. The results for $20 \%$ damping are shown in Table 1.

The results of the SIS optimization analysis for a non-isolated structure and an isolated structure allow making some principal and important conclusions. A widespread opinion that SIS should compensate all or most of the earthquake soil motion is a delusion. To achieve good isolation parameters of SIS it is quite enough to compensate much less than a half of anticipated soil displacements.

For the heavy and high NPP RB structure considered and the specific seismic motion defined by UHRS, the seismic input with $0.4 \mathrm{~g}$ PGA and the specific soil conditions used the optimal or close to optimal SIS should have:

- The first conditional natural frequency in the horizontal direction around $0.8-0.9 \mathrm{~Hz}$;

- The first conditional natural frequency in the vertical direction around 2.5-3.0 Hz;

- System damping within the range from $20 \%$ to $40 \%$ of the critical value.
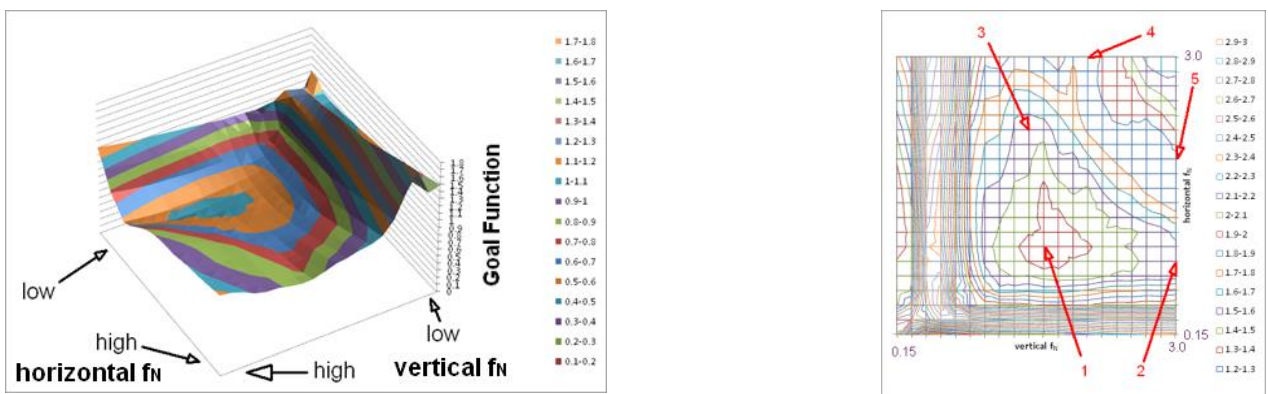

Figure 2. 3D and 2D SIS Goal Function surfaces for 20\% system's damping. 


\section{BASIC REQUIREMENTS FOR THE SIS AND OPTIMIZATION CHALLENGES}

In the new IAEA Report on seismic isolation [5], it has been noted that the main and very strict requirements should be applied for the base isolation devices in nuclear power applications. These requirements could be updated using some conclusions of the current study. Among them the most principal are as follows:

- SIS should be passive with the ability to provide RB with required natural frequencies in the horizontal and vertical directions in order to achieve the target RB isolation efficiency in all DoF;

- High SIS damping ability in the horizontal and vertical directions with the range of system damping at least $20 \%$ of critical damping;

- Long-term stability in the mechanical and damping properties under all design conditions (temperature, moisture, radiation, damaging substances, fire, flood, wind, air plane crash, blast, accidental and malevolent explosions, etc.);

- Confidence on SIS reliability under design and beyond design basis earthquakes; (Relevant Nuclear Codes and Standards are required performing of seismic probabilistic safety assessment in a row with deterministic one);

- Ability for a simple replacement of isolation and damping devices under operation conditions and to span loss of one or more devices;

- Ability to compensate short and long-term settlement (especially for structures located on soft and subsiding soils);

- Provide smooth distribution of the reaction forces and bending moments between a sub structure and a super structure;

- Availability of natural scale test results and an analytical model for SIS devices;

- SIS must recover quickly enough to withstand large aftershocks and an inherent property that passively re-centers the system.

A search conducted on the market of existing isolation devices and dampers has shown that all the requirements stated in a high degree correspond to isolation devices represented by elastic coil spring units, provide the structure with necessary 3D elastic properties independently in the vertical and horizontal directions. Thus the spring elements application will produce for the SIS necessary optimal spatial natural frequencies. For achieving required system's damping parameters it is quite appropriate to use separately installed 3D viscoelastic dampers. Level of damping in this case could be changed by its design and number of units in the SIS.

Figure 3 shows the newly developed high capacities (around to 500 metric tons) 3D spring units and 3D viscodampers, which could be used in designing and application of the optimal SIS for the NPP's $\mathrm{RB}$ and other heavy structures providing system's damping up to critical values. These natural scale components were subjected to a comprehensive individual static and dynamic testing at GERB, BAM and Eucentre test facilities.

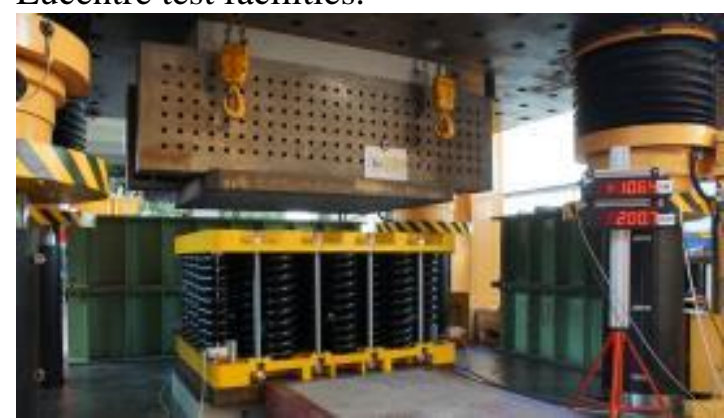

Figure 3. BCS 3D spring unit at BAM test rig

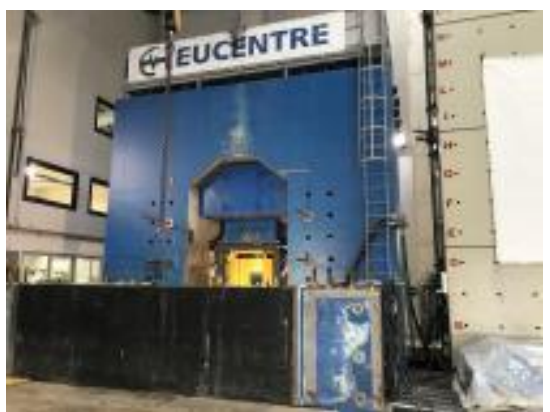

Figure 4. 3D viscodamper at Eucentre test facility 
SIS equipped with 3D elastic spring units and separately installed 3D viscodampers has the name of the Base Control System (BCS) and over the course of decades has been used for vibration control and seismic protection of SSC in nuclear power and civil engineering, Siepi (2015), Nawrotzki (2019).

\section{DETERMINISTIC ANALYSIS OF THE NPP RB WITH THE OPTIMUM SIS BCS}

The deterministic structural analysis has been performed on a set of generated time histories fit well enough to the design uniform hazard response spectrum (UHRS) obtained by probabilistic hazard assessment approach for some real NPP site. Figure 5 shows the in-structure seismic response spectra (reactor supports ISRS elevation) for horizontal and vertical seismic excitation having intensity of a safe shutdown earthquake (SSE) with PGA 0.4g. The figure shows a direct comparison of the ISRS for isolated reactor building and with rigidly supported reactor building having hard soil properties with two levels of system's damping $20 \%$ and $40 \%$ and two different factors of Goal function.

It is obvious that the efficiency of seismic isolation in horizontal direction is very high. For the vertical direction factor of isolation is also essential but little bit less than for horizontal one. This phenomenon could be evaluated as a unique result achieved by application of the optimal isolation parameters. It is well-known that all widespread isolation systems have essential coupling effects and provide serious amplification in the vertical direction under real 3D seismic excitation conditions, Furukawa (2012). Considering that a majority of components, equipment, distributions systems and piping have natural frequency above $2.0 \mathrm{~Hz}$ it should be concluded that the proposed optimal SIS has extremely high efficiency in the range 2.0 to $50 \mathrm{~Hz}$ in horizontal direction and definite efficiency in the vertical direction. On average, the optimal SIS provides the efficiency factor not less than 3 even in nonresonance zones and much higher at resonances.

Due to a high damping in optimal SIS a maximum seismic displacements are limited to $50 \mathrm{~mm}$ in horizontal direction and to $15 \mathrm{~mm}$ only in the vertical direction having initial $0.4 \mathrm{~g}$ site PGA. These values are much lower than allowable displacement in the known powerful spring units and viscoelastic dampers and give a chance not to use special compensators for distribution systems crossing isolated and nonisolated structures. This conclusion is correct also for beyond design basis earthquake (BDBE) conditions.
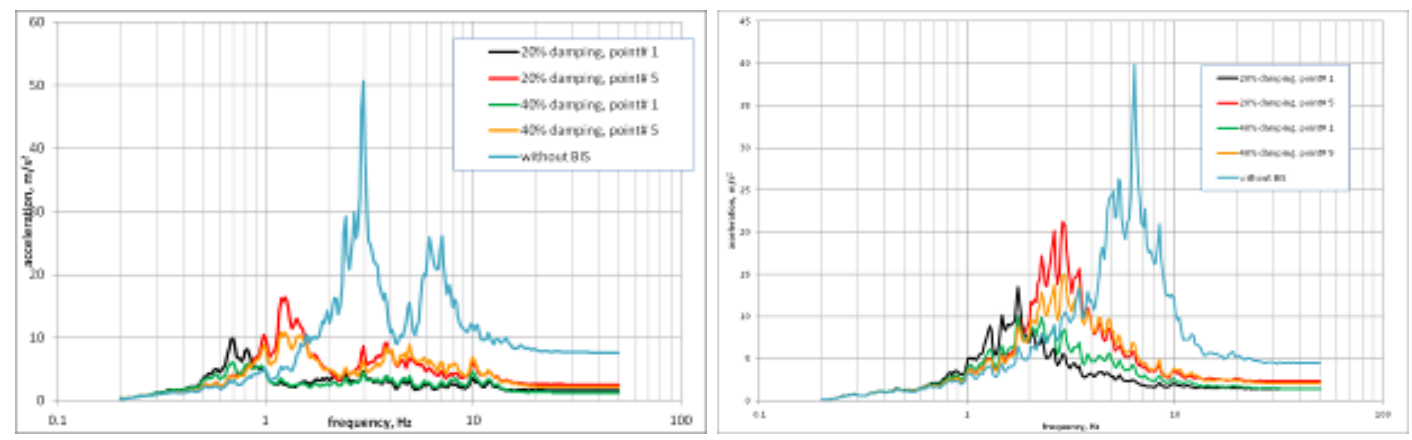

Figure 5. In-Structure Response Spectra for horizontal (left) and vertical (right) directions with different range of SIS system's damping (20-40\%) and Isolation Goal Function factors.

\section{PROBALISTIC SEISMIC SAFETY ASSESSMENT OF NPP EQUIPED WITH SIS BCS}

It is known that in the frame of probabilistic safety and risk analyses in nuclear power the earthquakes of much higher intensity with much lower frequency of occurrence should be considered. Such BDB impacts could lead to a failure of the SIS devices. A SIS failure is determined as the loss of its dead weight bearing capacity and incapability to return reactor building to the initial neutral position.

The idea of the "Defence in Depth" in its application to the SIS contains the requirement that available clearances in the 3D dampers should be less than elastic limits in spring units. Thus when gaps in the dampers are becoming close enough then an elastic-plastic behaviour in the damper's structure 
occurs as in the non-bearing element providing additional dissipation to the system. This mode exists up to the all dampers failure by its own failure mode. Only after that the spring units as the bearing elements shall be determined on its elastic-plastic behaviour and failure. Fragility analysis of the SIS was based on dynamic analysis using Monte-Carlo simulations. Calculated parameters for the SIS: $A m_{1}=2.0 \mathrm{~g}$ and $\beta_{c 1}=0.32$.

To assess an effectiveness and safety of the RB installed on the SIS BCS a simplified SPSA of the system «SIS-RB» was carried out. A failure logic model was based on the scheme shown in Figure 6.

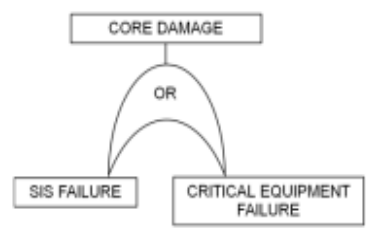

Figure 6. Failure logic model

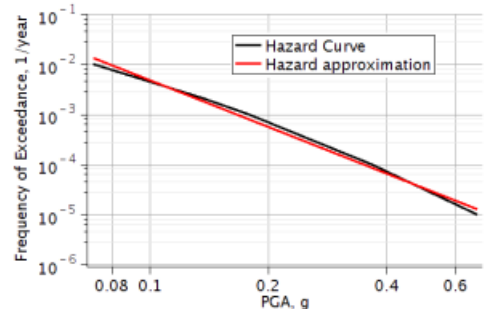

Figure 7. Typical seismic hazard curve

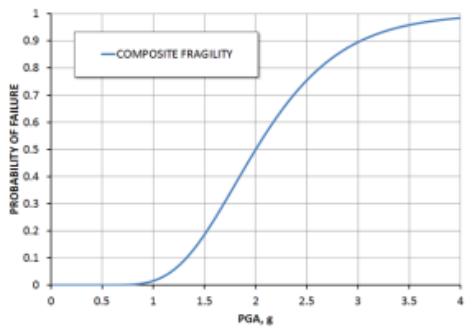

Fig 8. The composite fragility curve of the SIS BCS

It was assumed that the accident with core damage (CD) occurs either in the event of the SIS failure, or in the event of the critical systems failure leading directly to $\mathrm{CD}$ and located in the RB. Then

$$
P_{f}=P_{1}+P_{2}
$$

Where $P_{1}$ and $P_{2}$ are the frequencies (probabilities) of failure of the SIS and the critical components. It was also assumed that these are small values and failures are independent. Figure 7 and 8 shows a typical seismic mean hazard curve and the composite fragility curve characterizing the BCS.

Here is a widely used approximation for hazard curve $H(a) \approx K_{1} a^{-K_{h}}$. A typical range of variation for $K_{h}$ is $1.7-4.1$, Kennedy (1999). If the SSE [g] level corresponds to a frequency of $10^{-4}$ [1/year], then for the average parameter $K_{h}=2.9$ we obtain $K_{1}=1 \cdot 10^{-4} \cdot \mathrm{SSE}^{2.9}$ [1/ year]. Convolution with an approximated hazard curve:

$$
P_{f}=\int_{0}^{\infty} H(a) \frac{d P_{f \mid a}}{d a} d a=K_{1} A m^{-K_{h}} e^{\frac{1}{2}\left(K_{h} \beta_{c}\right)^{2}}
$$

\section{Case 1: RB without seismic isolation:}

In this case the design capacity of the unit expressed in HCLPF should not be less than SSE for the site: $H C L P F \geq S S E$. On the assumption that seismic capacity of the unit is completely determined and identical to the seismic capacity of the critical equipment, lognormal fragility model has a deviation $\beta_{c 2}=0.6, \quad A m_{2}=H C L P F \cdot e^{2.326 \beta_{c 2}}=4.0 \cdot H C L P F$, we have $\operatorname{CDF} P_{f} \leq P_{f}^{*}=8 \cdot 10^{-6}$ [1/year], which is acceptable for most Regulators.

Case 2. RB on seismic isolation:

The seismic response of the RB is decreased by the use of SIS, at various frequencies an efficiency is different. However, for the sake of simplicity and the possibility of further analysis it is assumed that the average efficiency of the SIS is 3: 


$$
\frac{S_{a}}{\hat{S}_{a}} \approx 3 \equiv n
$$

Here $S_{a}$ and $S_{a}$ are spectral accelerations on the RB's foundation before and after installation on a SIS. Then the probability of failure of the entire system "SIS-RB" can be expressed by the following formula:

$$
P_{f}(H C L P F, S S E)=P_{1}+P_{2}=K_{1} A m_{1}^{-K_{h}} e^{\frac{1}{2}\left(K_{h} \beta_{c 1}\right)^{2}}+n^{-K_{h}} K_{1} A m_{2}^{-K_{h}} e^{\frac{1}{2}\left(K_{h} \beta_{c 2}\right)^{2}},
$$

Again, the SIS parameters are as follows: $A m_{1}=2.0 \mathrm{~g}$ and $\beta_{c 1}=0.32$; for the unit itself: $\beta_{c 2}=0.6$, $A m_{2}=H C L P F \cdot e^{2.326 \beta_{c 2}}=4.0 \cdot H C L P F$.

The condition of equal safety in terms of CDF of units installed on the SIS and without SIS

$$
P_{f}(H C L P F, S S E) \leq P_{f}^{*}
$$

Forms the corresponding design domains in terms of nuclear safety (see Figure 11):

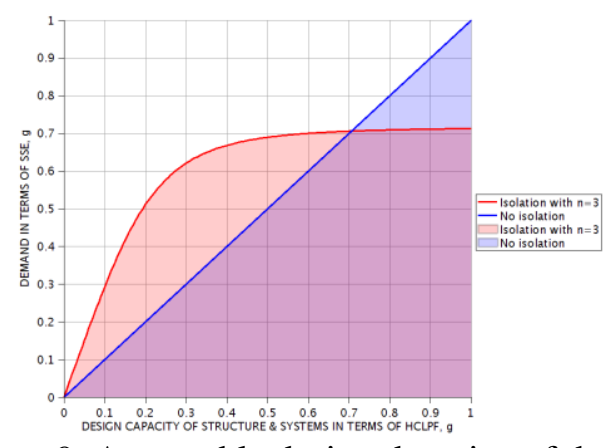

Figure 9. Acceptable design domains of the SIS

BCS application in terms of nuclear safety

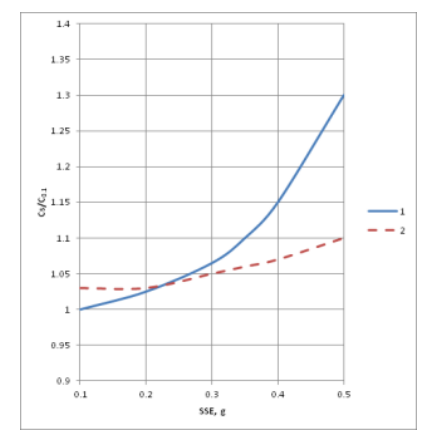

Figure 10. Design domains of the SIS BCS in terms of cost

Analysing the above Figures 9 and 10 we can come to the following conclusions:

- Having a design capacity up to $0.2 \mathrm{~g}$ we can select a site with seismicity up to $0.5 \mathrm{~g}$ in compliance with the safety requirements, provided that the safety related buildings are installed on the SIS BCS;

- The intersection point of the curves in Figure 9 is very characteristic. When considering the design of the NPP unit with HCLPF exceeding this value, the safety of the system «SIS-RB» will be determined by the seismic behaviour of the SIS itself. This point provides the feasibility limits for SIS BCS application:-

- The construction of NPP without SIS in areas of SSE 0.4g-0.6g is associated with a large investments in seismic safety measures for NPP's SSC, therefore the use of SIS for units with a low standard seismic design of PGA $0.2 \mathrm{~g}-0.25 \mathrm{~g}$ would be very beneficial both in safety and the construction cost issues, Figure 10.

\section{NATURAL SCALE SIS INVERSE SEISMIC ISOLATION TEST FACILITY (SIST)}


Beside individual SIS components testing required for validation of the BCS and/or other SIS elements and in order to perform testing of real structures with SIS a special inverse test rig (SIST) was developed and erected in Saint Petersburg, Russia for testing natural scale isolators with capacities from 1000 to $7500 \mathrm{kN}$ and different types of dampers. SIS components at SIST could be subjected to a full dead load and seismic displacements corresponding to big earthquakes motions, Figure 11.
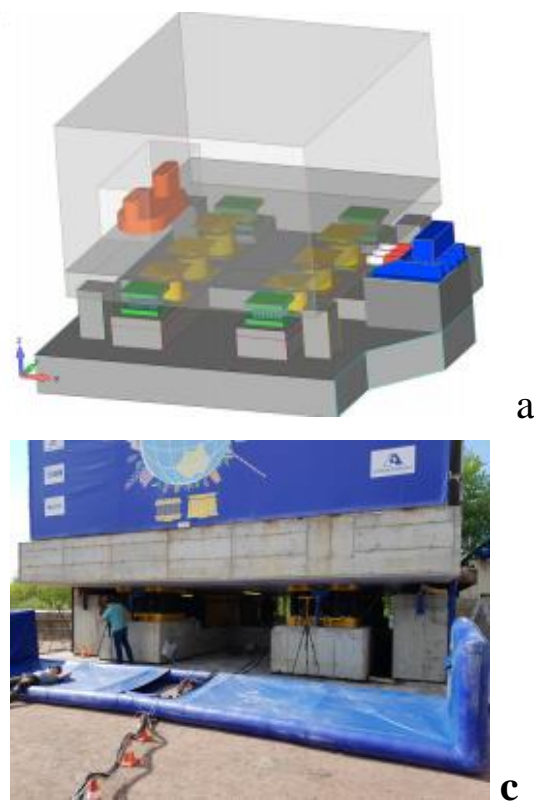

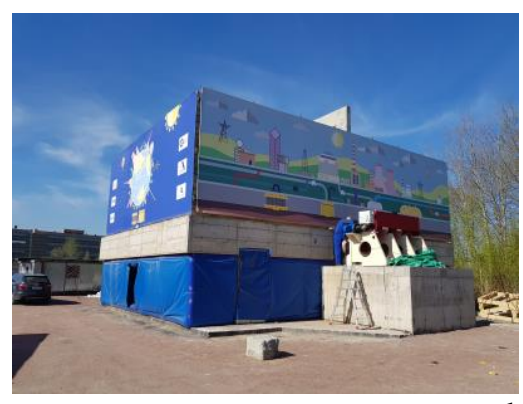

b

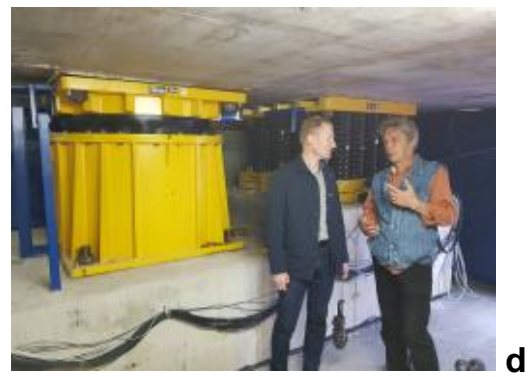

Figure 11. Inverse test rig SIST

a) SIST design with fast release pushing system in blue color; mechanical shaker in red; isolators in green; dampers in yellow b) SIST general View; c) 3D BCS spring units; d) 3D BCS Viscodamper.

CVS inverse approach means that the substructure is not shakinglike in shaking table approach but the superstructure is shaking at its natural frequencies providing SIS elements with a full scope of loads and deformations with amplitudes equal to full gravity, design basis (DBE) and beyond design earthquake (BDBE) conditions. SIST consists of a superstructure with variable mass form 1000 t to 3000 $\mathrm{t}$, massive foundation with known soil parameters for investigating of soil-structure interactions, pushimg quazidynamic system $1100 \mathrm{kN}$ capacity with fast release system and $+/-150 \mathrm{~mm}$ displacements, testing SIS elements (not less 4 isolators and variable number of dampers) and mechanical vibration machine. First three natural frequencies and modes of the system using BCS elements are shown in Figure 12.

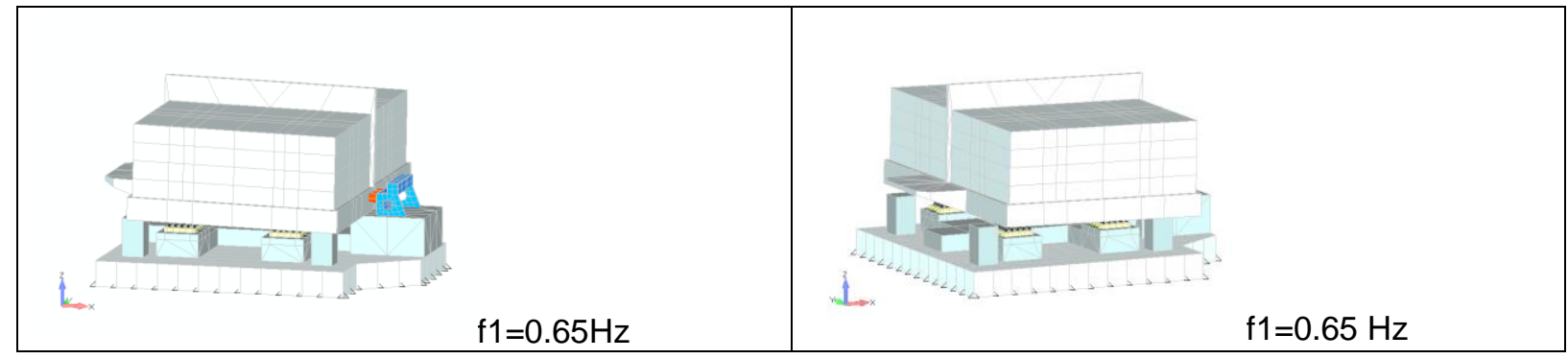




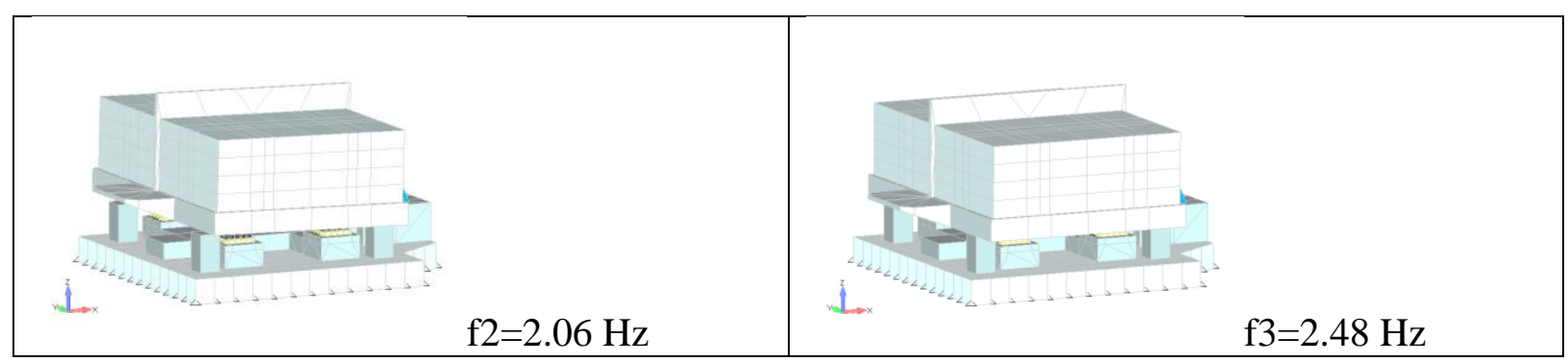

Figure 12. Natural frequencies and modes of SIST using 3D BCS isolation system.

SIST features and goals:

- Natural scale dynamic and seismic testing of base isolation systems under full dead load and displacement conditions;

- Reproduction of building structure behaviour by shaking at natural frequencies of isolated system (rocking, horizontal and vertical modes and its combination);

- Definition of a real non-linear SIS behaviour and system damping;

- Confirmation and validation of analysis procedures and results for base isolated structures;

- Investigation of SIS SSI effects with known and definite soil characteristics of the site.

First tests at SIST started in December 2017 through 2019 and have shown its functionality and operability. It was shown that 3D BCS isolation approach using coil spring isolation elements and 3D viscodampers provides to the superstructure previously defined optimal parameters with any necessary system's damping in the range of $10 \%$ to the critical values around $100 \%$ system damping and even more. Figure 13 shows that under similar conditions with the same initial parameters the behavior of the system without dampers is radically different from the case with the use of viscodampers and thus real conditions arise for the selection and application of optimal damping parameters for each particular structure and isolation system.

At the SIST it is possible to test any types of seismic isolators, snubbers and dampers subjected to a full dead load capacity and real seismic displacements by shaking the superstructure at its natural frequencies and modes of vibration.

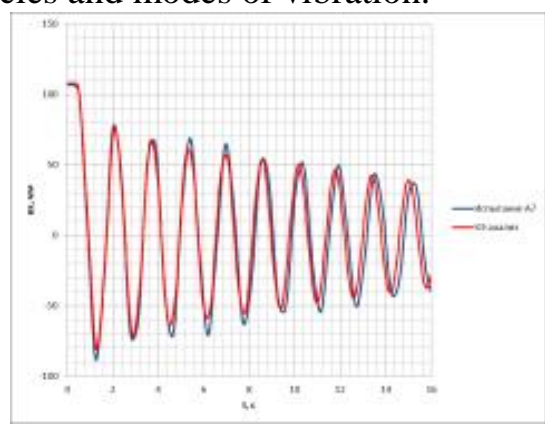

Figure 13. BCS SIST test without dampers. SSE displacements. Low system's damping provided by spring units only.

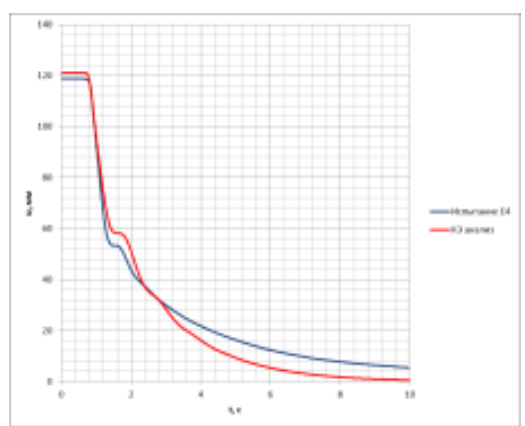

Figure 14. BCS SIST test with dampers. SSE displacements. High system's damping over critical for some main modes of vibration.

\section{GENERAL COST EVALUATIONS IN THE SIS APPLICATIONH}

Application of the SIS in nuclear power promises great benefits in safety upgrading and even could be very cost effective by the following reasons. The average cost of a 1000-1200 MWt NPP of standard design for PGA of 0.1-0.2g could be assumed as $\$ 6.0$ billion in 2018 year prices and it essentially and non-linearly increases with a site PGA, Stevenson $(1981,2003)$. 
According to these evaluations the total cost of seismic engineering, the cost of seismically restrained equipment, components and piping and its maintenance plus the construction costs for an NPP with PGA $0.4 \mathrm{~g}$ could be considered as at least $10 \%$ of the total NPP cost. For PGA $0.6 \mathrm{~g}$ it would achieve $20 \%$ of the overall NPP cost. Just for information, a standard aseismic NPP design for high seismicity zones presumes installation of around 2000 seismic restraints, (snubbers, etc.) having maintenance cost times to its primary cost. Only this "seismic restraining" cost could be estimated around $\$ 100 \mathrm{mln}$. for the life cycle of NPP built in a high seismic region. Thus the total NPP seismic design and seismic construction costs could be estimated over $\$ 1000 \mathrm{mln}$. for sites with PGA over $0.4 \mathrm{~g}$. Our estimation has shown that SIS application would save at least 50\% of the above sum or about $\$ 500 \mathrm{mln}$ for the NPP sites considering some cost increasing in the design and slotted foundation construction and the cost of SIS devices itself. So the total benefit in the SIS applying could be evaluated at least as $7 \%$ of the total cost of an NPP in a high seismic zone location. Some specific estimation on the issue is shown in Figure 10.

\section{CONCLUSIONS}

1. The proposed optimization approach in the definition of basic characteristics of Seismic Isolation Systems has shown new possibilities for essential increasing in 3D base isolation efficiency including the vertical direction and a possibility for a dramatic dropping of relative displacements of the sub- and super-structures of the isolated building.

2. Both deterministic structural analysis and probabilistic safety assessment have shown that the SIS BCS approach based on using of the coil spring isolation devices and 3D viscodampers having optimal or close to optimal parameters is feasible and highly efficient. This SIS could be implemented for any building structures in high seismicity areas and sites having the SSE PGA over $0.25 \mathrm{~g}$ and up to $0.7 \mathrm{~g}$.

3. It was confirmed high efficiency of the BCS seismic isolation system by individual natural scale testing of the BCS elements springs and dampers and by real structural tests at the unique SIST test facility.

\section{REFERENCES}

Furukawa S., Sasaki T., Sato E., Okazaki T., Keri L., and Ryan K. (2012). Comparison of Vertical Dynamic Response Characteristics of Two Base-isolated Buildings based on Full-scale Shaking Table Test, Proceedings of 15WCEE, Lisbon, Portugal.

Kennedy Robert P. (1999). Overview of Methods for Seismic PRA and Margin Analysis Including Recent Innovations, Proceedings of the OECD/NEA Workshop on Seismic Risk, Tokyo.

Nawrotzki P. et al.3-D Base control systems for the seismic protection of structures. Proceedings of the 16WCSI World Conference on Seismic Isolation, 1-6 July 2019, Saint Petersburg, Russia.

Ochi Y., Kashiwazaki A., and Kostarev V. (1990). Application of high viscous damper on piping system and isolation floor system, Proceedings of the 9th European Conference on Earthquake Engineering, Moscow.

Siepe D., Nawrotzki P. Horizontal and vertical isolation of seismic and aircraft impact Proceedings of the $14^{\text {th }}$ World Conference on Seismic Isolation, Energy Dissipation and Active Vibration Control of Structures, 9-11 September 2015, San Diego, USA.

Sollogoub P., Editor in Chief, International Atomic Energy Agency (IAEA) (2018). Technical Report. Seismic Isolation Systems for Nuclear Installations, Viena, Austria.

Stevenson J. (1981). NUREG/CR-1508. Evaluation of the cost effects on Nuclear Power Plant construction resulting from the increase in seismic design level, U.S. Nuclear Regulatory Commission.

Stevenson J. (2003). Historical development of the seismic requirements for construction of Nuclear Power Plants in the U.S. and worldwide and their current impact on cost and safety, Transactions of the 17thSMiRT Conference, 17-22 August, Prague, Czech Republic.

Vasilyev P., (2013). Methods for calculation of the reactor building with seismic isolation system under dynamic loads, Transactions, SMiRT-22, San Francisco, USA. 